\title{
A VISÃO SISTÊMICA DA JUREMA PRETA (MIMOSA TENUIFLORA) NO MUNICÍPIO DE SÃO JOÃO-PE
}

\author{
Renner Ricardo Virgulino Rodrigues ${ }^{1}$
}

\author{
Maria Betânia Moreira Amador ${ }^{2}$
}

\begin{abstract}
RESUMO
O trabalho trata da questão do verde arbóreo em ambientes rurais, refletindo sobre a importância e as utilidades da Jurema Preta (Mimosa tenuiflora) presente na paisagem rural do município de São João$\mathrm{PE}$, através da visão sistêmica. Objetiva-se a análise dessa árvore em sua abrangência local, sob os pontos de vista ambiental e econômico, inserida na área rural do município no âmbito do verde da paisagem agreste. Procede-se como metodologia o levantamento bibliográfico, ida ao campo para observação, registros fotográficos e imagens de satélite, mostrando-se necessário a interdisciplinaridade e a percepção. Nesse contexto, a árvore em discussão é de pequeno porte, atingindo cerca de $5 \mathrm{~m}$ de altura; apresenta casca castanho-escura com acúleos, endêmica da Caatinga nordestina. No contexto econômico, a população usa a Jurema, da raiz aos galhos, com a produção de carvão e lenha devido ao alto teor calorífico. O tronco de madeira densa e de grande durabilidade fornece estacas para construção e manutenção de cercas e currais, além da própria delimitação do território da propriedade. No contexto natural menciona-se a utilização da sombra e alimentação para o gado bovino, caprino e ovino. Conclui-se que a Jurema Preta presente no meio rural traz benefícios importantes para os são-joanenses, uma vez que pode ser utilizada de várias formas tanto no aspecto ambiental quanto econômico, dentre elas: produção de estacas, carvão e lenha, no contexto econômico; sombra e abrigo no contexto natural.
\end{abstract}

PALAVRAS-CHAVE: Visão Sistêmica. Jurema Preta. São João-PE.

\section{SYSTEMIC VISION OF BLACK JUREMA (MIMOSA TENUIFLORA) ARE IN THE MUNICIPALITY OF JOHN-PE}

\begin{abstract}
SUMMARY
The paper deals with the green of the tree issue in rural areas, reflecting on the importance and utility of the Black Jurema (Mimosa tenuiflora) present in the countryside of São João-PE by systemic view. The objective is the analysis of this tree in your local coverage under the environmentally and economically, inserted in a rural area of the municipality under the green harsh landscape. It comes as the methodology literature, going to the field for observation, photographic records and satellite imagery, being necessary interdisciplinarity and perception. In this context, the tree in dispute is small, reaching about 5 meters high; has dark brown bark with thorns, endemic to northeastern Caatinga. In the economic context, the population uses the Jurema, root and branch, with the production of coal and firewood due to the high calorific content. The trunk of dense wood and provides great durability stakes

\footnotetext{
${ }^{1}$ Graduando do Curso de Licenciatura em Geografia da UPE/Campus Garanhuns. E-mail: rennervirgulino@outlook.com.

${ }^{2}$ Doutora em Geografia; Professora Adjunta da UPE/Campus Garanhuns. E-mail: betaniaamador@yahoo.com.br
} 
for construction and maintenance of fences and corrals, besides the very definition of the territory of the property. In the natural context mentions the use of shade and food for cattle, goats and sheep. We conclude that the Black Jurema present in rural areas has important benefits for the are-joanenses, since it can be used in various ways both environmental aspect as economic, such as: production of cuttings, coal and wood, in the economic context; shade and shelter in the natural context.

KEYWORDS: Systemic View. Jurema Black. St. John-PE.

\section{VISIÓN SISTÉMICA DE JUREMA NEGRO (MIMOSA TENUIFLORA) ESTÁN EN EL MUNICIPIO DE JUAN-PE}

\section{RESUMEN}

El artículo trata el verde de la edición de árboles en las zonas rurales, lo que refleja la importancia y utilidad de la Negro Jurema (Mimosa tenuiflora) presentes en el interior de São João-PE por visión sistémica. El objetivo es el análisis de este árbol en su cobertura local bajo la vista ambiental y económico, inserta en una zona rural del municipio bajo el verde paisaje áspero. Se presenta como la literatura metodología, ir al campo para la observación, registros fotográficos y de imágenes de satélite, siendo la interdisciplinariedad y la percepción necesaria. En este contexto, el árbol de la diferencia es pequeña, llegando a unos 5 metros de altura; tiene la corteza de color marrón oscuro con espinas, endémico noreste Caatinga. En el contexto económico, la población utiliza la Jurema, raíz y rama, con la producción de carbón y leña debido al alto contenido calórico. El tronco de madera densa y ofrece grandes apuestas de durabilidad para la construcción y mantenimiento de cercas y corrales, además de la propia definición del territorio de la propiedad. En el contexto natural menciona el uso de sombra y alimento para ganado, cabras y ovejas. Llegamos a la conclusión de que el presente Negro Jurema en las zonas rurales tiene importantes beneficios para el son-joanenses, ya que se puede utilizar de varias maneras tanto aspecto ambiental como económico, tales como: producción de esquejes, carbón y madera, en el contexto económico ; sombra y refugio en el contexto natural.

PALABRAS CLAVE: Ver sistémica. Jurema Negro. San Juan-PE.

\section{INTRODUÇÃO}

Diante das observações sobre a composição da paisagem rural do município de São João-PE, verificou-se a presença da árvore denominada Jurema Preta (Mimosa tenuiflora), a qual se trata de uma espécie endêmica e que faz parte do quadro natural da região. Nesse sentido, julgou-se ser importante induzir discussões sobre a sua importância para a natureza e para sociedade numa perspectiva de paisagem verde rural no referido município, numa perspectiva ambiental.

A Geografia, através de suas categorias de análise paisagem e lugar, oferecem oportunidades para a realização de um estudo dessa natureza. Ressaltando-se a pertinência de uma abordagem sistêmica frente às necessárias integrações de caráter multidisciplinar passíveis de visualização na presente proposta. 
Tendo em vista, algumas áreas do Agreste que apresentam insuficiência de estudos e pesquisas, principalmente nessa temática, salientando-se que o município de São João está inserido na área de abrangência do semiárido brasileiro e o trabalho que se apresenta enquadra-se no âmbito de um projeto maior, intitulado "O Verde na Paisagem Agreste de Pernambuco: Urbano e Rural” e faz parte do GESSANE- Grupo de Estudos Sistêmicos do Semiárido do NordEste.

É importante fazer um estudo dessa natureza para conhecer a realidade junto ao município de São João e tentar entender as principais razões que levam a preservação e/ ou erradicação do verde existente no espaço rural, no qual se acha a árvore em estudo.

Justifica-se ainda pela relevância de se refletir e socializar a compreensão do objeto de estudo para evidenciar e discutir a questão da preservação e da sua função para a paisagem e para sociedade. Registra-se, ainda, a informação de que a área constituída, predominantemente, de Jurema Preta vem, ao longo das últimas décadas, cedendo lugar para a agropecuária.

Os resultados poderão contribuir para o município no sentido de formação e informação, além de trazer mais conhecimento sobre árvores do semiárido e subsidiar possíveis políticas públicas voltadas para a questão da conservação e/ou preservação, ou ainda, práticas de convivência com o semiárido.

Objetivou-se analisar a Jurema Preta (Mimosa tenuiflora) em sua abrangência local sob o ponto de vista ambiental, inserida na área rural do município de São João$\mathrm{PE}$, num contexto sistêmico, no âmbito das questões verdes da paisagem agreste. Bem como, identificar áreas com predominância de Juremas Preta e sua concentração dessas no município; Observar sua utilização, tanto num contexto natural, quanto econômico e refletir sobre sua importância para o espaço rural.

A metodologia utilizada materializou-se pelo levantamento bibliográfico, bem como a ida a campo para observações. Mostrando-se necessário a interdisciplinaridade e o uso da percepção, meios importantes para análise da paisagem e estudos voltados para a temática ambiental. Houve também, registros fotográficos para tomada de algumas cenas importantes para realização da pesquisa e imagens de satélite (Google Earth) para melhor visualização das áreas estudadas. 
O estudo foi realizado em São João-PE (Mapa 1), localizado no interior de Pernambuco, Mesorregião do Agreste Pernambucano e Microrregião de Garanhuns.

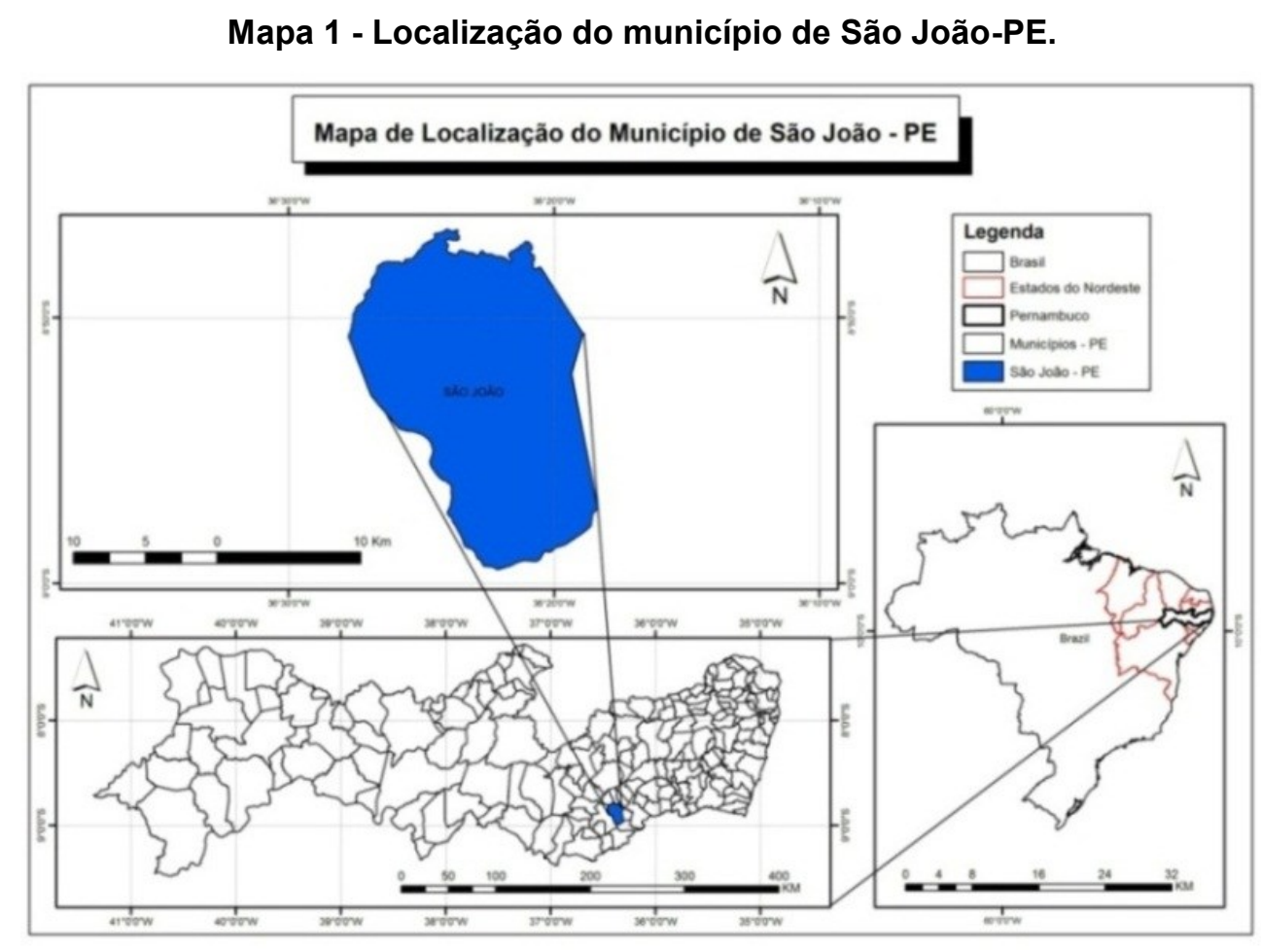

Fonte: RODRIGUES, 2013.

São João está localizada a uma latitude 0852'32" sul e a uma longitude $36^{\circ} 22^{\prime} 00^{\prime}$ oeste, com altitude de 716 metros. Sua área territorial é de $258,334 \mathrm{~km}^{2}$, limitando-se com Jupi e Jucati ao norte; Palmeirina ao sul; Angelim a leste e, Garanhuns a oeste. A distância à capital pernambucana, Recife, é de $236 \mathrm{~km}$.

Seu bioma é a Mata Atlântica e se encontra incluído na unidade geoambiental das Superfícies Retrabalhadas, com relevo dissecado e vales profundos. Apresenta vegetação composta por Florestas Subperenefólias e com partes de Florestas Hipoxerófilas. Encontra-se inserido na bacia hidrográfica do Rio Mundaú (IBGE, 2010).

O clima da região onde o município de São João está localizado, segundo o PTRP- Plano Territorial de Rede Produtiva, é o Tropical Semiúmido - Quente com média maior que $18^{\circ} \mathrm{C}$ em todos os meses do ano (04 e 05 meses secos). É também 
encontrado o clima Tropical Semiúmido - Subquente com média entre $15^{\circ} \mathrm{C}$ e $18^{\circ} \mathrm{C}$ em pelo menos 01 mês por ano (04 e 05 meses secos), o que é caracterizado como microclima - região de Garanhuns. (PTRP, 2012).

Segundo Rodrigues et al (2014), “a base da economia do município gira em torno da produção agrícola, tendo a cultura do feijão mais expressiva, recebendo o status de maior produtora de feijão do estado de Pernambuco. Além do feijão, também, tem-se o cultivo de milho e mandioca" (RODRIGUES et al, 2014, p. 118).

De acordo com o IBGE - Instituto Brasileiro de Geografia e Estatística, em 2010, São João apresentava população absoluta de 21.312 habitantes, com estimativa de 22.162 para 2013.

Justifica-se a escolha do município pelas relações afetivas do autor com o lugar de origem, no caso específico, ser residente da área rural de São João. Essas relações de afeto são tratadas pelo geógrafo Yi-Fu Tuan (1980), o qual em sua literatura aborda a topofilia, termo criado por ele mesmo, onde diz que:

A palavra "topofilia" é um neologismo, útil quando pode ser definida em sentido amplo, incluindo todos os laços afetivos dos seres humanos com o meio ambiente material. Estes diferem profundamente em intensidade, sutileza e modo de expressão. A resposta ao meio ambiente pode ser basicamente estética: em seguida, pode variar do efêmero prazer que se tem de uma vista, até a sensação de beleza, igualmente fugaz, mas muito mais intensa, que é subitamente relevada. A resposta pode ser tátil: o deleite ao sentir o ar, água, terra. Mais permanentes e mais difíceis de expressar, são os sentimentos que temos para com um lugar, por ser o lar, o locus de reminiscências e o meio de se ganhar a vida. (TUAN, 1980, p. 107).

Diante do exposto, é importante salientar a percepção que se tem do lugar onde vive, ressaltando suas belezas, as culturas, as tradições. Nesse contexto, acredita-se que para ler e entender o mundo é preciso o conhecimento de categorias de análises, no caso da Geografia, aqui salientado, o lugar.

A percepção, discutida também na Psicologia, vem como auxilio de compreensão para a Geografia, pois a partir do processo de perceber o sujeito passa a compreender a si mesmo, bem como outros elementos à sua volta. Tuan (1980) descreve que "percepção é tanto a resposta dos sentidos aos estímulos externos, 
como a atividade proposital, em que certos fenômenos são claramente registrados, enquanto outros retrocedem para a sombra ou são bloqueados" (TUAN, 1980, p. 4).

Para entendimento das funcionalidades da Jurema Preta no espaço geográfico de São João, optou-se pela perspectiva sistêmica e, também, o pensamento complexo. Assim, toma-se como referência Amador (2011), que aponta sobre essa abordagem na Geografia, tanto na pesquisa quanto na atividade profissional, assim:

\begin{abstract}
Admitindo-se certo grau de compreensão a respeito, acredita-se que o profissional geógrafo tem a oportunidade de exercer suas atividades seja na docência, seja no âmbito técnico de forma integrada, buscando a visualização das partes no todo e o todo nas partes. (AMADOR, 2011, p. 86).
\end{abstract}

Portanto, buscou-se a visualização das partes no todo e o todo nas partes de forma integrada na realização do trabalho.

Ainda, para a autora, sobre a perspectiva sistêmica afirma que,

Nessa ótica, parte-se da premissa de que se deve abordar um determinado problema a partir da ideia de sistema que, embora esteja respaldada no Holismo, permite trabalhar a complexidade presente no contexto pela linha metodológica do geossistema e do agrossistema, no caso da Geografia. (AMADOR, 2011, p. 86).

Nessa concepção, busca-se entender as relações estabelecidas da árvore no meio ambiente a qual está inserida com a população rural que faz uso diferenciado da mesma, bem como as percepções existentes, trazendo assim, a relação homemnatureza.

Sobre o pensamento complexo, Amador (2011) afirma que "pensar complexamente requer trabalhar com o objeto em contexto, ampliar o foco e conseguir visualizar sistemas amplos. Tira-se o foco exclusivo do elemento e incluemse as relações" (AMADOR, 2011, p. 86).

Justifica-se ainda, a escolha da árvore, que se deu pela mesma ser nativa da região de estudo, apresentando várias formas de utilização e não dispor de trabalhos voltados para os objetivos tratados no trabalho proposto.

O objeto de estudo é a Jurema Preta (Mimosa tenuiflora (Willd.) Poiret), de sinônimo botânico Mimosa hostilis Benth, espécie arbórea-arbustiva, pioneira, típica e 
encontrada frequentemente no bioma Caatinga, pertencente à família Fabaceae, da ordem das Fabales, ocorrendo nas regiões semiáridas do Brasil principalmente encontrada nos estados do Nordeste brasileiro (Figura 1).

Figura 1 - Jurema Preta, localizada no Sítio Queimada do Milho, São João-PE.

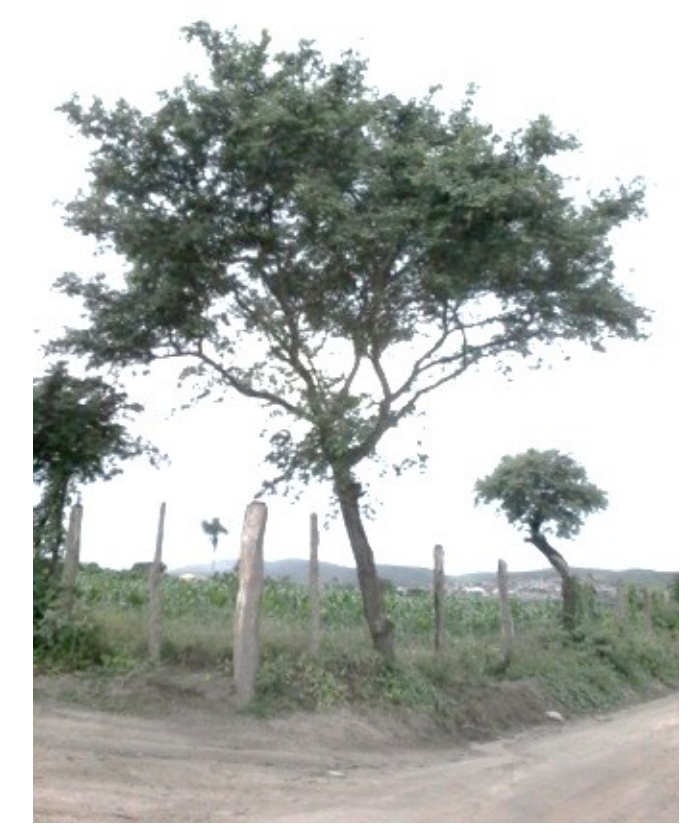

Fonte: RODRIGUES, 2014.

Cabe considerar que a Jurema apresenta vários tipos, entre as quais a Jurema Preta. Dessa forma, diferencia-se da Jurema Branca (Mimosa verrucosa ou Mimosa ophtalmocentra Mart. Ex Benth) e da Jurema Vermelha (Mimosa arenosa (Willd.) Poir).

Segundo Vasconcelos Sobrinho (1970, p. 76), "a Mimosa hostilis Benth, Jurema Preta - Leguminosa - é árvore de pequeno porte até 5 metros de altura por 0,20 centímetros de diâmetro; casca escura com acúleos. Madeira muito dura, castanho-escura, geralmente utilizada para carvão em fundições, dado o seu alto poder calorífico". Ainda em relação à madeira, Faria (1984, p. 84), aponta que "a madeira possui boa qualidade em função do alto peso específico básico que é de $0,91 \mathrm{~g} / \mathrm{cm}^{3}$, o que classifica como excelente madeira para o carvão". 
Silva et al (2012, p. 218), também salienta a funcionalidade da madeira da Jurema Preta e assinala que "sua madeira é bastante rígida e resistente com alta durabilidade para obtenção de estacas e apresenta facilidade para queima, se tornando ótima fonte de energia". A justificativa pela escolha e preferência dos agricultores pela estaca da Jurema estão relacionadas com sua grande durabilidade e resistência natural, também pela resistência que ela tem contra praga de cupins. (PAES, et al., 2007).

Salientando-se ainda, segundo Vasconcelos Sobrinho (1970, p. 76), "da casca de suas raízes, faziam certas tribos de índios - Carajás e outras -, bebida estupefaciente e alucinatória, com características semelhantes à dos ampliadores de consciência". Bebida na qual, também se chama "jurema" ou "vinho da jurema".

De acordo com Dias e Souto (2007, p. 268) "a Jurema Preta é a leguminosa para ser introduzida com sucesso nas pastagens, sem a proteção de suas mudas e na presença do gado".

Tem-se na Jurema potencial para a produção de taninos, substância utilizada para curtimentos de peles. Segundo Paes et al (2006):

\begin{abstract}
A Jurema Preta, em função da quantidade de taninos apresentada em sua casca e sobretudo por ser uma espécie de alta densidade florística no Semiárido brasileiro, apresenta potencial para ser utilizada como produtora de taninos. No entanto, são necessárias pesquisas para avaliar a qualidade dos taninos para o curtimento e recurtimento de peles e também para outros usos. (PAES et al. 2006, p. 461).
\end{abstract}

Diante disso, a Jurema Preta apresenta várias utilidades no âmbito econômico, social e natural. Sua importância dar-se desde a raiz às folhas, cabendo vários estudos relacionados ao assunto para conhecimento do mesmo apresentado suas variadas potencialidades.

A Jurema Preta também serviu de inspiração musical. A música intitulada "Jurema Preta", cantada por uma das maiores célebres e importante cantora nordestina, Elba Ramalho, nos traz a importância do tronco da árvore para confecção de calçados, dado a sua dureza e durabilidade. 


\author{
Jurema Preta \\ "Ô tamanqueiro eu quero um par, eu quero um par \\ eu quero um par de tamanco pra eu andar \\ Ô tamanqueiro eu quero um par, eu quero um par \\ eu quero um par de tamanco pra eu andar \\ Ô lá em casa tem um pé de pau \\ um pé de pau com nome Jurema Preta \\ mais pra cima tem o diabo de uma velha \\ uma velha quebrando as espuletas \\ mais pra cima tem o diabo de um macaco \\ um macaco fazendo tanta careta \\ mais pra cima tem o diabo de um valente \\ um valente com um punhal na mão direita \\ mais pra cima tem o diabo de um soldado \\ tem um soldado tocanso tanta corneta. [...]"
}

Elba Ramalho.

Disponível em: http://www.kboing.com.br/elba-ramalho/1-1130934/

Acesso em: em 13 de maio de 2014.

\title{
DESENVOLVIMENTO
}

\section{ÁREAS COM PREDOMINÂNCIA DA JUREMA PRETA EM SÃO JOÃO-PE}

Em São João-PE, a área com maior predominância da Jurema Preta se encontra na região norte, também, conhecido pela população local de "agreste", já que o município dispõe de duas regiões fitogeográficas, o Agreste e a Mata Úmida.

No "agreste" pode se observar, atualmente, que a vegetação arbórea existente está bastante alterada pela ação antrópica, que antes predominavam grandes juremais hoje vem reduzindo a fragmentos e dando lugar principalmente às roças das pequenas propriedades de agricultores familiares que, geralmente, plantam feijão, milho e mandioca para subsistência e a comercialização do excedente, para isso precisam de espaço para a produção das culturas mencionadas. Também, dá lugar às árvores frutíferas, a exemplo, cajueiros, mangueiras, entre outras... e para pastagens. A Jurema é encontrada isolada ou em pequenos fragmentos dentro das propriedades. 
Nas imagens de satélites a seguir evidenciam as informações expostas acima.

Figura 2 - Imagem de satélite com área marcada com predominância da Jurema Preta, sítio Vaca Morta, São João-PE.

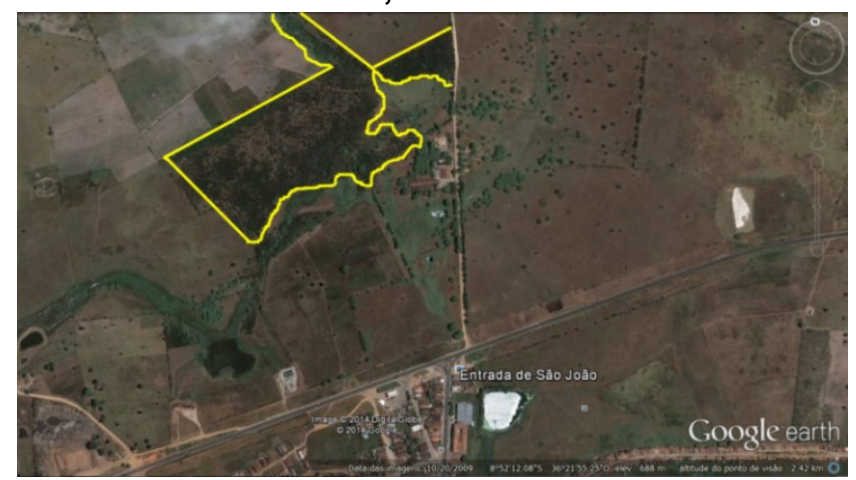

Fonte: GOOGLE Earth. Adaptação: RODRIGUES, 2014.

A figura 2 ilustra a presença de Juremas (traçada pela linha amarela) nas proximidades da entrada da cidade. É evidenciada sua redução para as pastagens das fazendas e roças em suas adjacências. Também é observado a presença da exótica algarobeira (Prosopis juliflora) em verde claro, no mesmo espaço.

Figura 3 - Imediações de uma escola municipal e a concentração de Jurema Preta.

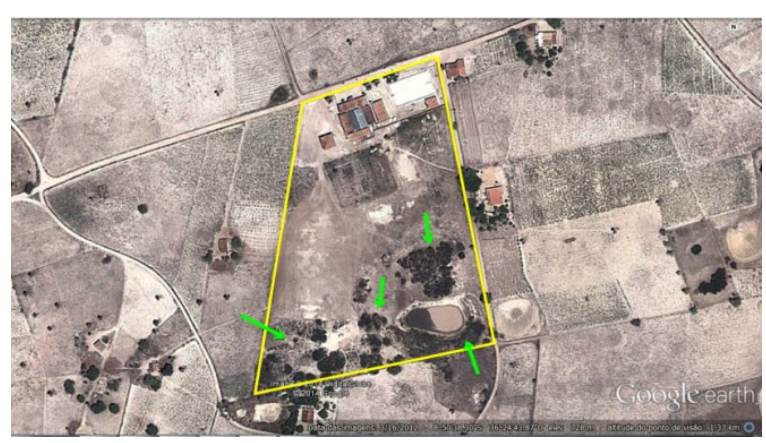

Fonte: GOOGLE Earth. Adaptação: RODRIGUES, 2014.

A imagem de satélite (Figura 3) ilustra o contexto espacial de uma instituição de ensino localizada no Sítio Anda Só. A linha amarela indica a área territorial total da escola e as setas verdes mostra a predominância de Jurema Preta na área. Atualmente, a paisagem desse espaço escolar se encontra alterada pela ação antrópica, preservando apenas poucas árvores devido a não utilização desse espaço. 
Em contrapartida, pode-se observar a pouca e/ou a inexistência de árvores nas proximidades onde existe a produção agrícola. Isso é frequentemente visto em outras localidades onde o verde arbóreo vem dando espaço à agropecuária. A presença da árvore poderia ser atrelada à Educação Ambiental, trazendo conhecimento e possíveis maneiras de preservação da mesma.

Figura 4 - Presença da Jurema Preta em dois sítios em São João.

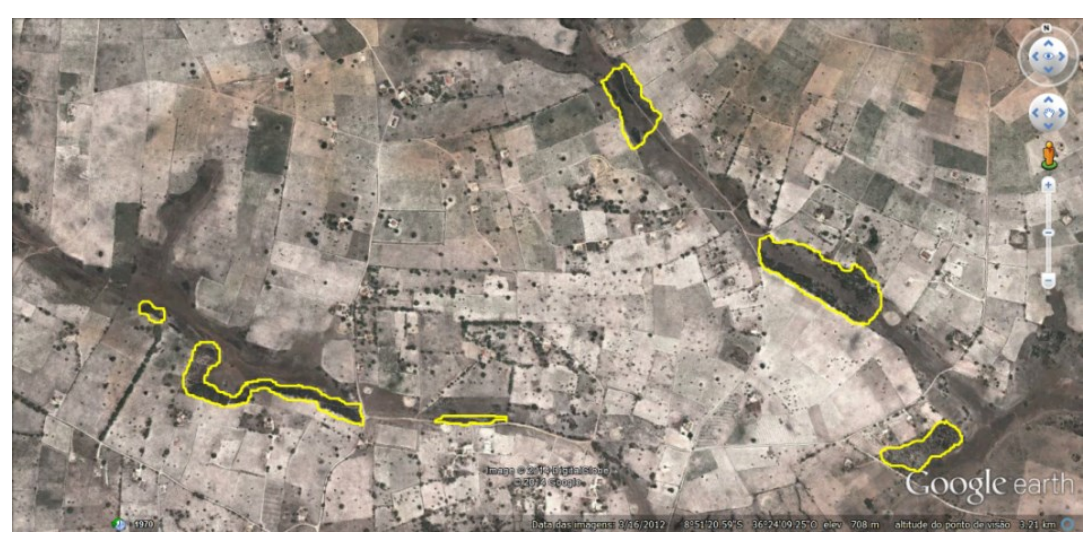

Fonte: GOOGLE Earth. Adaptação: RODRIGUES, 2014.

A imagem acima (Figura 4) aborda áreas com frequência da Jurema. Os sítios que são abordados são: Sítio Várzea da Pedra e Várzea do Barro. A árvore predomina mais nas proximidades de dois riachos temporários. As linhas amarelas contemplam áreas com juremais mais densos, porém, a árvore está mais espacializada e isolada.

No sul do município, "mata", ao contrário de pequenas propriedades no norte, predominam as fazendas de gado bovino, que nesse contexto, na visão dos proprietários precisam de grandes áreas para pasto e alternativa encontrada é a devastação da mata nativa (atualmente encontra-se apenas alguns resquícios da Mata Atlântica) e nessa destruição encontra-se incluída, em pouca quantidade, a Jurema Preta que servirá para a construção das cercas das fazendas.

\section{UTILIZAÇÕES DA JUREMA PRETA EM SÃO JOÃO NUM CONTEXTO ECONÔMICO E NATURAL}




\section{CONTEXTO ECONÔMICO}

As principais utilidades no contexto econômico da Jurema Preta pelos munícipes de São João estão: a produção de estacas, carvão e lenha. Já no contexto natural, a Jurema desempenha papel importante em relação à habitação de diferentes insetos, grande diversidade de aves, pequenos roedores e pequeno animais que habitam em pequenos juremais no município. Também a presença da árvore em áreas de pastos exerce a função de sombreamento para animais domesticados, como exemplos, o gado bovino, equino, caprino e ovino.

A escolha da madeira da Jurema Preta para a produção de estaca (Figura 5) dar-se pela grande resistência, durabilidade e densidade que a mesma dispõe. Essas estacas são utilizadas para construções e manutenções de cercas (Figura 6) em áreas rurais para delimitação de território e separação de áreas de pastos das agrícolas dentro das propriedades. Cada estaca custa em média $R \$ 10,00$, o preço varia de acordo com o diâmetro da mesma.

Figuras 5 e 6: Estacas e cercas construídas com Jurema Preta.
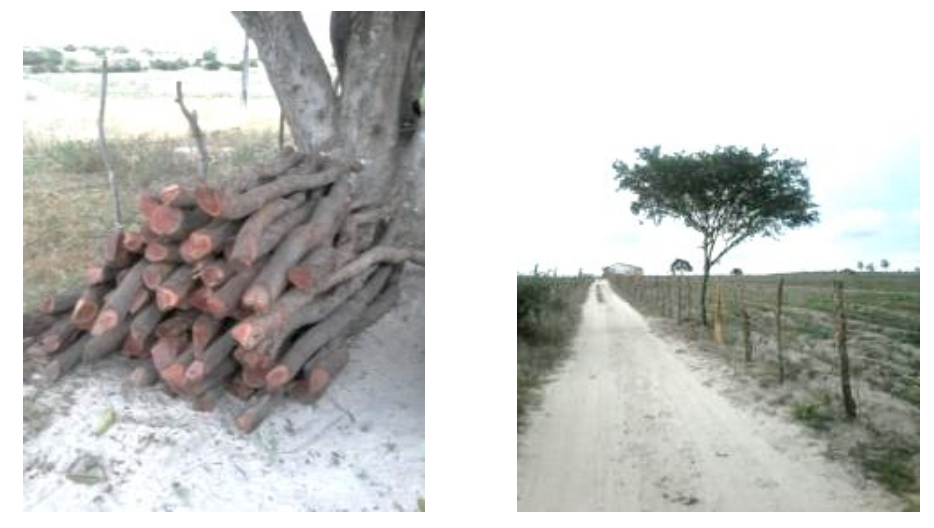

Fonte: RODRIGUES, 2013.

Devido ao alto teor calorífico que a madeira da Jurema apresenta, a árvore torna-se uma excelente fonte energética para a produção de carvão e lenha. O carvão é produzido em valas cavadas na própria propriedade, popularmente essas valas abertas são denominadas "caeira” (Figura 7) pelos agricultores. 
Figura 7 - "Caeira” no Sítio Várzea do Barro.

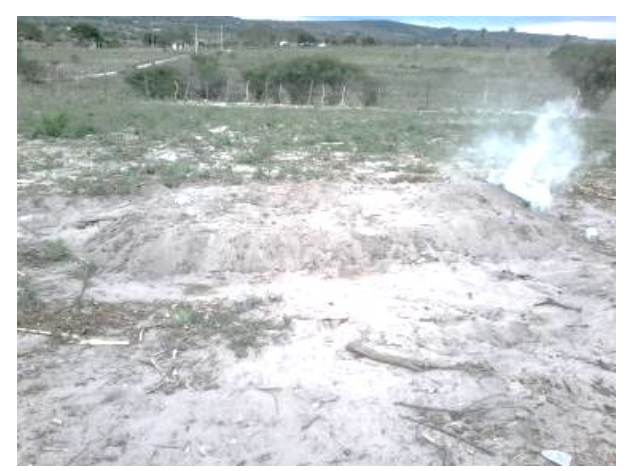

Fonte: RODRIGUES, 2014.

Nessas "caeiras", inicialmente são colocadas as madeiras e após é colocado uma camada de palha e areia onde é ateado fogo e, depois algumas semanas o produto (carvão) é retirado.

A lenha (galhos e pedaços de madeiras) é utilizada para abastecer os fornos das casas-de-farinha presentes nos sítios. Cada saca de carvão custa em média $\mathrm{R} \$$ 24,00. Preço corrente de 2014.

\section{CONTEXTO NATURAL}

No contexto natural a Jurema Preta desempenha importantes funções. Muitas aves buscam nos galhos da árvore um local propício para se abrigarem, nesses locais constroem seus ninhos e ali criam laços com outros elementos presentes no ambiente. Foram identificados vários tipos de aves que buscam a Jurema, entre elas estão: a rolinha, o anu, a casaca-de-couro e a popular "garrancheira", além de outras. Essas mesmas aves usam o próprio graveto espinhoso e seco da árvore que cai e serve para a confecção dos ninhos (Figura 8).

Figura 8 - Ninho de uma Casaca-de-couro, Sítio Várzea da Pedra. 


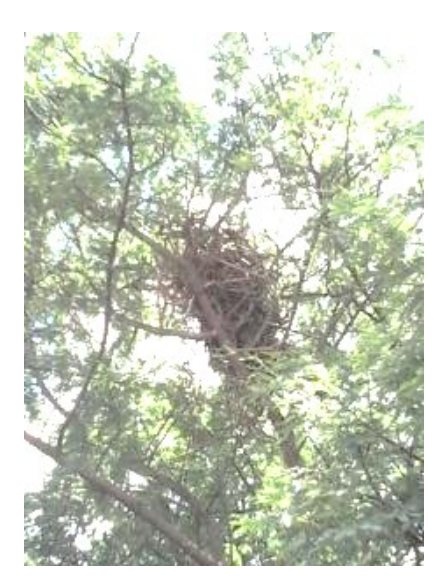

Fonte: RODRIGUES, 2013.

Também, foram observados uma diversidade de insetos e pequenos animais presentes nos juremais, entre esses animais estão as raposas e pequenos roedores nativos da região, como exemplo, o gabiru e o preá.

Outras funções naturais da árvore estão a sombra e a alimentação (Figuras $9 \mathrm{e}$ 10 , respectivamente).

Figuras 9 e 10 - Bovinos debaixo de uma sombra e caprinos se alimentando das folhas da Jurema Preta, respectivamente.
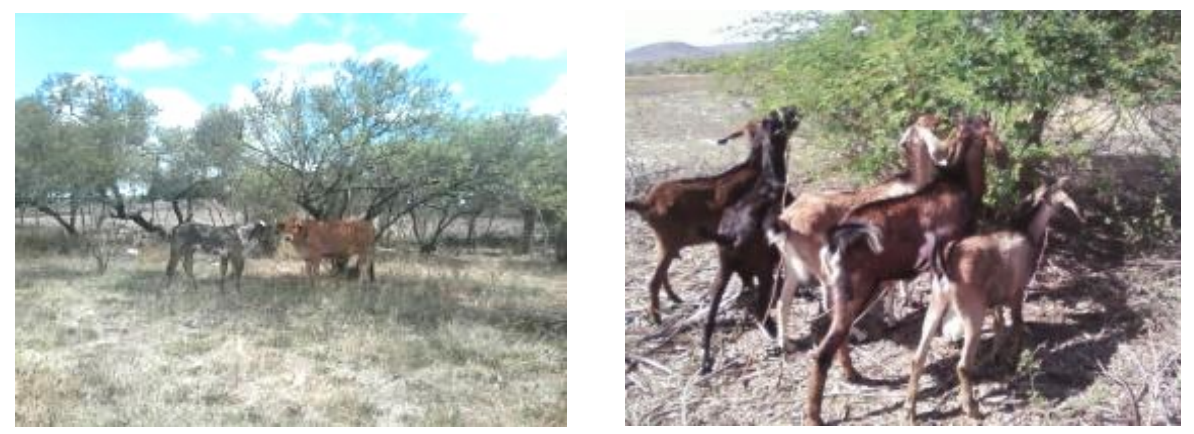

Fonte: RODRIGUES, 2013.

Muitos animais buscam debaixo da Jurema um lugar agradável para descanso e ao mesmo tempo, por ser palatável, se alimentar da mesma. Como exemplos desses animais estão os gados bovinos, caprinos, ovinos e equinos. 


\section{CONCLUSÃO}

Dentre suas variadas potencialidades e funcionalidades constatadas, a Jurema Preta torna-se de grande importância para a área rural do município de são João. Foi constatado que as utilizações mais comuns dela são para produção de estacas, carvão e lenha, no contexto econômico. No contexto natural ela é muito utilizada para sombreamento dos animais.

Foi verificado que a Jurema vem perdendo a cada ano seu espaço original para a agropecuária, o que pode colocá-la no futuro em risco de aniquilação, mesmo com sua característica de regeneração e crescimento rápido. Seu espaço dá lugar à pequenas e grandes roças onde há o cultivo de culturas importantes para a economia do município, principalmente o feijão, milho e mandioca, bem como às pastagens, deixando apenas algumas árvores, ou nenhuma.

Diante do exposto, os camponeses que tem a árvore em suas propriedades devem olhar como um elemento importante não só pra paisagem rural, mas como elemento verde importante para biodiversidade em sua abrangência e começar a entender, através da sustentabilidade, possíveis caminhos para a conservação e manejo adequado para que outras gerações vindouras também possam usufruir desse bem importante para a sociedade e para o meio ambiente.

\section{REFERÊNCIAS}

AMADOR, Maria Betânia Moreira. Sistemismo e sustentabilidade: questão interdisciplinar. São Paulo: Scortecci, 2011.

DIAS, P.F; SOUTO, S.M. Jurema Preta (Mimosa tenuiflora): Leguminosa arbórea recomendada para ser introduzida em pastagens em condições de mudas sem proteção e na presença do gado. Revista da FZVA. Uruguaiana, v. 14, n 1, p. 258-272. 2007. Disponível em:

<http://revistaseletronicas.pucrs.br/ojs/index.php/fzva/article/viewFile/2492/1951> Acesso em: 19 ago. 2013.

FARIA, W. L. F. A Jurema Preta (mimosa hostilis, Benth) como fonte energética do semi-árido do Nordeste-carvão. 1984. 128 f. Dissertação de Mestrado (Mestrado em Ciências Florestais) Universidade Federal do Paraná, Curitiba, PR, 1984. Disponível em:

<http://dspace.c3sl.ufpr.br/dspace/bitstream/handle/1884/25171/D\%20\%20FARIA,\%20WASHINGTON \%20LUIZ\%20FONSECA.pdf?sequence=1> Acesso em: 18 ago. 2013.

GOOGLE Earth. Figuras 2, 3, e 4. 2014. 
IBGE. Histórico de São João. 2010. Disponível em:

<http://www1.ibge.gov.br/cidadesat/painel/historico.php?lang=\&codmun=261320\&search=pernambuco| sao-joao|infograficos:-historico> Acesso em: 11 jan. 2014.

IBGE. População de São João. 2010. Disponível em:

http://www1.ibge.gov.br/cidadesat/xtras/perfil.php?lang=\&codmun=261320> Acesso em: 11 jan. 2014.

PAES, J. B. et al. Resistência natural de sete madeiras ao cupim subterrâneo (Nasutitermes corniger Motsch.) em ensaio de preferência alimentar. Revista Brasileira de Ciências Agrárias, Recife, v. 2, n. 1, p. 57-62. 2007. Disponível em:

$<$ http://www.agraria. $p r o . b r / s i s t e m a / i n d e x . p h p ? j o u r n a l=a g r a r i a \& p a g e=a r t i c l e \& o p=v i e w \& p a t h[]=42 \&$ path[] =70> Acesso em: 18 ago. 2013.

et al. Viabilidade técnica dos taninos de quatro espécies florestais de ocorrência no

Semiárido brasileiro no curtimento de peles. Ciência Florestal, Santa Maria, v. 16, n. 4, p. 453-462.

2006. Disponível em: < http://cascavel.cpd.ufsm.br/revistas/ojs-

.2.2/index.php/cienciaflorestal/article/view/1927/1169> Acesso em: 04 fev. 2014.

PTRP - PLANO TERRITORIAL DE REDE PRODUTIVA. Rede Territorial Produtiva do Feijão:

Agreste Meridional e Central, Estado de Pernambuco. Recife/PE, 2012. Disponível em:

<http://www.prorural.pe.gov.br/downloads/PTRT\%20Feijao/PTRP\%20FEIJAO.pdf> Acesso em: 13 jan. 2014.

PREFEITURA DE SÃO JOÃO. Dados gerais do município. Disponível em:

<http://saojoao.pe.gov.br/dados-gerais-do-municipio/> Acesso em: 30 dez. 2013.

RAMALHO, Elba. Jurema Preta. Disponível em: <http://www.kboing.com.br/elba-ramalho/1-1130934/> Acesso em: 13 de maio de 2014.

RODRIGUES, Renner Ricardo Virgulino; AMADOR, Maria Betânia Moreira. Reflexões Sistêmicas sobre a Jurema Preta (Mimosa tenuiflora) com enfoque no município de São João/PE. Periódico Eletrônico Fórum Ambiental da Alta Paulista-ISSN 1980-0827, Tupã, v. 9, n. 7, p. 181-186. Resumo Expandido apresentado no IX Fórum Ambiental da Alta Paulista, Estância Turística de Tupã/SP, 2013. Disponível em:

<http://www.amigosdanatureza.org.br/publicacoes/index.php/forum_ambiental/article/viewFile/556/581> Acesso em: 20 jan. 2014.

RODRIGUES, Renner Ricardo Virgulino; SANTOS, Raí Vinícius; AMADOR, Maria Betânia Moreira. Reflexões Sistêmicas sobre a Jurema Preta (Mimosa tenuiflora) com enfoque no município de São João-PE. In: AMADOR, Maria Betânia Moreira (Org.). O Verde na Paisagem Agreste de

Pernambuco: Urbano e Rural. 1. ed. Tupã: ANAP, 2014. p. 112-128. Disponível em:

<http://www.amigosdanatureza.org.br/livros/livro/cod/83> Acesso em: 23 de julho de 2014.

SILVA, E. M. et al. Diagnóstico do uso de leguminosas em propriedades rurais no município de Aparecida-PB. Revista Verde de Agroecologia e Desenvolvimento Sustentável. Mossoró-RN, v. 7, n.3, p. 212-217. 2012. Disponível em:

<http://www.gvaa.org.br/revista/index.php/RVADS/article/viewFile/1765/pdf_532> Acesso em: 18 ago. 2013.

TUAN, Yi-Fu. Topofilia - Um estudo da percepção, atitudes e valores do meio ambiente. São Paulo: DIFEL, 1980.

VASCONCELOS SOBRINHO, J. As regiões naturais do Nordeste, o meio e a civilização. Recife: CONDEPE, 1970 (Reimpressão, 2005). 